\title{
A ÉTICA DO CUIDADO COMO ALTERNATIVA À ÉTICA DE PRINCÍPIOS: DIVERGÊNCIAS ENTRE CAROL GILLIGAN E NEL NODDINGS
}

\author{
THE ETHICS OF CARE AS AN ALTERNATIVE TO THE ETHICS OF PRINCIPLES: \\ DISAGREEMENTS BETWEEN CAROL GILLIGAN AND NEL NODDINGS
}

\author{
TÂNIA A. KUHNEN' ${ }^{1}$ \\ (UFSC - Brasil)
}

\begin{abstract}
RESUMO
Este artigo apresenta uma análise crítica acerca da concepção de "ética do cuidado" proposta por Nel Noddings. O objetivo é averiguar os pontos nos quais Noddings distancia-se da abordagem teórica sobre o desenvolvimento moral de Carol Gilligan. O ponto central da divergência entre ambas situa-se no fato de que Noddings defende a proposta de uma ética do cuidado em detrimento de uma ética de princípios, ao contrário do que é sugerido por Gilligan por meio da noção de complementaridade entre as duas vozes distintas da moral por ela identificadas, a saber, a masculina e a feminina. A partir da discussão realizada, tem-se que não é possível conceber uma ética do cuidado como uma alternativa à ética de princípios com base nas pesquisas desenvolvidas por Gilligan.

Palavras-chave: complementaridade, desenvolvimento moral, ética do cuidado, ética de princípios, gênero.
\end{abstract}

\begin{abstract}
This article presents a critical analysis about the conception of "ethics of care" proposed by Nel Noddings. The aim of this work is to determine the points at which Noddings departs from Carol Gilligan's theoretical approach about the moral development. The main disagreement between them lies in fact that Noddings defends an ethics of care as opposed to an ethic of principles. That runs counter to what is suggested by Gilligan through the idea of complementarity between the two distinct moral voices identified by her, namely the male and female voices. After the discussion we conclude that based on the research developed by Gilligan we can not conceive an ethics of care as an alternative to the view of ethics of principles.

Keywords: complementarity, ethics of care, ethics of principles, gender; moral development.
\end{abstract}

\section{INTRODUÇÃO}

O ponto de referência de grande parte dos filósofos e filósofas feministas que defendem a abordagem teórica da "ética do cuidado" é a obra de Carol Gilligan, In a Different Voice: Psycological Theory and Women's Development (1982) ${ }^{2}$. Nesse livro, Gilligan apresenta um estudo acerca do desenvolvimento psicológico moral de meninos e meninas ao longo de vários anos. Ela sustenta a tese de que o desenvolvimento psicológico de meninos difere do de meninas, sendo que na vida adulta as mulheres em geral formam uma voz moral distinta da que é desenvolvida pelos homens.

O problema encontrado por Gilligan nas teorias psicológicas acerca do desenvolvimento moral humano é o de que essa voz ligada ao feminino comumente não é percebida, ou então é silenciada por ser considerada inferior quando comparada com a voz masculina, geralmente associada 
aos homens e tomada como padrão de medida ${ }^{3}$. Enquanto a voz masculina direciona-se para o desenvolvimento de propostas éticas pautadas em princípios imparciais e direitos, a voz feminina aponta para um modo diverso de falar sobre problemas morais, baseado na experiência feminina dos relacionamentos de cuidado. Essa experiência é considerada feminina por ter sua origem ligada ao ciclo de vida da mulher e, mais especificamente, ao cuidado maternal primário que gera um sentimento de conexão entre mãe e filha. É a partir dessa experiência que as mulheres desenvolvem uma abordagem moral voltada para o cuidado e a responsabilidade nas relações.

Importa notar, conforme salienta Mitchell, que Gilligan não tenta definir a moral ou explicar sua gênese. Ela sustenta apenas que as mulheres desenvolvem uma abordagem relacional da moralidade em virtude de uma forte identificação entre a mãe (a cuidadora primária) e a filha. Por meio do reconhecimento dessa ligação, Gilligan explora a voz moral distinta da mulher, atendo-se ao modo como elas tendem a resolver conflitos morais ${ }^{4}$. Apesar de enfocar esse processo moral decisório feminino, Gilligan não pretende impor algum modelo de moralidade.

Embora críticas venham sendo realizadas a essa compreensão da moralidade, Gilligan tem também sido apoiada no campo do pensamento filosófico por autoras como Annette Baier, que corrobora o entendimento de Gilligan, afirmando que parece realmente haver uma voz feminina diferente daquela voz moral padrão dos filósofos ${ }^{5}$.

Dentre as autoras feministas que recorreram a Gilligan como ponto de apoio para conceber uma "ética do cuidado" tem-se Nel Noddings. Da mesma forma que Gilligan, Noddings argumenta que a ética "tem se concentrado no raciocínio moral [...], no estabelecimento de princípios e naquilo que pode ser logicamente derivado deles" $"$. Ainda conforme a autora, a ética é discutida na linguagem masculina, baseada em princípios que visam assegurar os direitos individuais, a integridade e a justiça. A voz feminina, direcionada para o cuidado nas relações humanas, é silenciada nesse processo $^{7}$. Noddings propõe sua teoria do cuidado nas relações como forma de substituir o masculino pelo feminino no campo da moralidade.

Apesar de se poder identificar uma proximidade entre o pensamento de Gilligan e o de Noddings, o objetivo desse artigo consiste em averiguar os pontos nos quais Noddings distanciase da abordagem da moral desenvolvida por Gilligan. Inicialmente, cabe ressaltar que ao propor a diferença existente entre o desenvolvimento moral masculino e o feminino, Gilligan não defende a necessidade de implementar uma ética do cuidado em detrimento de uma ética de princípios, ao contrário do que é sugerido por Noddings.

\section{A REJEIÇÃO DOS PRINCÍPIOS UNIVERSAIS NA PROPOSTA TEÓRICA DE NEL NODDINGS}

A ética do cuidado em Noddings é construída a partir de uma crítica aos princípios e leis 
universais da moral, geralmente formuladas por filósofos do sexo masculino. Ela rejeita os princípios e as regras enquanto guias centrais da ação ética, pois eles podem ser ambíguos e instáveis, bem como a própria universalizabilidade dos julgamentos morais, apontando para uma necessária preservação da singularidade dos encontros humanos e para a satisfação moral do outro, somente possível por intermédio da manutenção e do florescimento de uma relação de cuidado ${ }^{8}$. Noddings coloca claramente a ética do cuidado como uma abordagem alternativa à ética de princípios.

No entender de Noddings, a ética como raciocínio moral guiado pela forma de pensar masculina leva à violência e à destruição. Muitos acontecimentos, como as guerras, são justificados em nome de princípios. A linguagem dos princípios é a linguagem do pai, daquele que procura proteger-se através de direitos por sentir-se "separado" dos outros". É uma linguagem que se afasta da afetividade presente nas relações e que, por isso, segundo Noddings, aproxima-se de um “racionalismo romântico" e distancia-se do tipo de ética possível em um mundo real ${ }^{10}$.

O cuidado, por sua vez, leva em conta uma visão feminina da ética, baseada na receptividade, na relação, na sensibilidade e na memória do cuidado recebido. As mulheres guiadas por esse modo feminino de pensar a ética sentem-se responsáveis pela manutenção da ligação que mantém com os que lhe são próximos. A concretização do cuidado nessas relações é a forma de realização dessa responsabilidade.

De acordo com Noddings, essa visão feminina da ética considera o fato de que a maior parte das mulheres não aborda os problemas morais como problemas de princípios, de raciocínio e de julgamento, mas leva em conta os elementos concretos da situação específica ${ }^{11}$. A mulher é guiada pela preocupação em satisfazer o outro de quem cuida moralmente. Por isso, ela colocase "o mais próximo possível de situações concretas" e assume "uma responsabilidade pessoal pelas escolhas a serem feitas" ${ }^{12}$. Em outras palavras, a moralidade da responsabilidade dispensa, em muitas situações, a existência de princípios e leis absolutas e universais - característicos dos sistemas éticos desenvolvidos pelos homens, que não se sentem seguros nas relações e por isso necessitam de regras e direitos para se proteger. A relação, na proposta de Noddings, é considerada “ontologicamente básica e a relação do cuidado como eticamente básica" ${ }^{13}$. A preocupação com a manutenção da relação afetiva de cuidado está, portanto, acima dos princípios e normas morais no modo de pensar feminino da moral e constitui-se a base da ética do cuidado.

No entender de Noddings, a experiência feminina da ética da responsabilidade e do cuidado nas relações não permite aplicar princípios universais, uma vez que a própria manutenção do círculo de relações e de sua continuidade restringe a ação ética a um mundo controlável, diferentemente da ética masculina do ideal do amor universal ou da justiça universal ${ }^{14}$. Assim, tudo depende do ideal de cuidar que motiva a ação ética, cuja origem situa-se no "cuidado natural"15 de uns para com os outros e no afeto recebido, que gera as lembranças do melhor cuidado a serem reproduzidas ${ }^{16}$. 
No desejo de cuidar inexistem princípios absolutos que orientem o agir moral, argumenta Noddings. O cuidado não é regido por regras, princípios e prescrições que determinem o tipo de comportamento a ser adotado em dadas condições. A ética do cuidado preocupa-se em saber que tipo de questões devem ser levantadas em cada situação específica para que se possa buscar as respostas adequadas ao caso. Dessa maneira, o cuidado molda-se contextualmente nas relações e não por meio de julgamentos morais abstratos ${ }^{17}$. Por conseguinte, o ideal de um cuidado universal ou um cuidado voltado para todos leva a uma abstração que nada diz sobre o que fazer em situações concretas. Em virtude disso, torna-se inviável, sustenta Noddings, um cuidar de todos. A ética do cuidado limita a obrigação de cuidar às relações:

\footnotetext{
Nossa obrigação é limitada e delimitada pela relação. Na esfera humana, nunca somos livres para abandonar nossa preparação para cuidar; mas, na prática, se estamos encontrando aqueles de nossos círculos internos adequadamente como cuidadores e recebendo aqueles ligados aos nossos círculos internos por cadeias formais de relação, limitaremos muito naturalmente os chamados à nossa obrigação ${ }^{18}$.
}

Portanto, a obrigação da atitude do cuidado limita-se àqueles que fazem parte das relações próximas, como a família e os amigos, sendo que para além desses não há dever de cuidar. Em parte, isso se deve à exigência de reciprocidade entre aquele que cuida e o seu objeto do cuidado, defendida por Noddings. A reciprocidade não significa que o objeto do cuidado também precise ser um cuidador, mas que ele contribua de forma livre e espontânea para a relação ao reconhecêla, completando essa relação por meio de atitudes de aceitação ${ }^{19}$. Por reciprocidade, a autora não entende algo no sentido contratual através do qual alguém forneceria um cuidado para receber algo em troca. Não há exigência dessa simetria nas relações de cuidado, ao contrário, elas geralmente se apresentam de forma assimétrica, o que permite ao próprio agente cuidador perceber de que modo contribui para o bem-estar daquele que é cuidado ${ }^{20}$.

Tendo apresentado em linhas gerais a concepção de ética do cuidado de Noddings como visão alternativa e substituta à ética de princípios - e até mesmo incompatível com ela -, passa-se a análise crítica dessa concepção, com base na abordagem da moralidade apresentada por Gilligan.

\section{O DISTANCIAMENTO DA PROPOSTA TEÓRICA DE NODDINGS EM RELAÇÃO À ABORDAGEM DE GILLIGAN}

Em alguns aspectos, Noddings aproxima-se da abordagem de Gilligan, uma vez que ambas admitem a existência de uma distinção entre o modo como mulheres e homens lidam com problemas morais. Antes de Noddings, Gilligan já havia pontuado o fato de que um problema moral comumente 
emerge para as mulheres quando há conflito na responsabilidade em várias relações. A resolução do conflito visa garantir a manutenção dos relacionamentos de cuidado. Para tanto, as mulheres em geral não recorrem a um modelo de pensamento formal e abstrato, ou seja, não procuram satisfazer critérios de pensamento baseados em princípios de orientação para a justiça, mas baseiam-se na responsabilidade nas relações ${ }^{21}$.

Gilligan ainda sustenta que ao se afastarem de princípios e procedimentos formais, o imperativo moral que guia as ações das mulheres "é uma ordem para cuidar dos outros, uma responsabilidade de discernir e aliviar os problemas reais" ${ }^{22}$. Por isso, mulheres conduzem os dilemas morais abstratos para um contexto mais próximo, reconhecendo que independentemente da decisão tomada, o resultado será o sofrimento de alguém. Isso, por sua vez, gera uma dificuldade para chegar a respostas definitivas nas questões morais, uma vez que prevalece a relutância em fazer os outros sofrerem e se reconhece as limitações do próprio julgamento moral.

No entanto, diferentemente de Noddings, Gilligan não pretende que a abordagem feminina da ética, isto é, o modo feminino de resolver problemas morais constitua-se em uma alternativa a ética de princípios universais e abstratos. É com base nesse aspecto que a proposta da ética do cuidado de Noddings distancia-se da investigação realizada por Gilligan, que objetivou evidenciar a existência de dois modos diferentes de conceber a moralidade, um feminino e um masculino, com o fim de evitar que o modo feminino fosse ignorado nas teorias morais, ou considerado inferior ao masculino. Gilligan não sugeriu suplantar o modo masculino de pensar a moralidade pelo feminino, como o faz Noddings. Ao contrário, a inquirição de Gilligan aponta para a coexistência das duas "vozes" da moralidade.

Nesse sentido, pode-se sustentar, a partir de Gilligan, que a busca pelo espaço para a denominada "voz feminina" na sociedade não significa que uma ética do cuidado deva ser implementada em detrimento de uma ética de princípios e direitos. A autora defende claramente a complementaridade entre uma ética de princípios e uma ética do cuidado:

[...] o desenvolvimento de ambos os sexos pareceria arrastar uma integração de direitos e responsabilidades através da descoberta da complementaridade destas diferentes visões. Para as mulheres, a integração dos direitos e das responsabilidades realiza-se através de uma compreensão lógica psicológica das relações [...]. Para os homens, o reconhecimento pela experiência de que existe a necessidade de uma responsabilidade mais activa nos actos nascidos da preocupação com os outros, corrige a potencial indiferença de uma moralidade de não interferência e desvia a atenção da lógica para as consequências da escolha ${ }^{23}$.

Como se observa, a maturidade no desenvolvimento moral humano de homens e de mulheres é completa quando ambos compreendem as diferenças entre a moralidade masculina e a feminina, mas também a possibilidade de conciliar essas diferenças. Do mesmo modo que a atitude do 
cuidado pode ser compartilhada pelos homens, os princípios e regras universalizáveis podem ser partilhados pelas mulheres. Em outras palavras, a necessidade de respeitar os direitos dos outros e de cuidar dos outros torna-se, portanto, integrada. Trata-se de uma forma nova de ver a moralidade, caracterizada por uma compreensão de dois pontos de vista diferentes, o que permite atingir a convergência entre as duas vozes morais, apesar de ambas originarem inicialmente a tensão entre direitos e responsabilidade no desenvolvimento humano. As duas vozes da moralidade são duas experiências que estão, no fim, ligadas ${ }^{24}$.

Ao construir uma compreensão ampla da noção de desenvolvimento, pautada na inclusão do desenvolvimento moral humano de ambos os sexos, Gilligan abre o caminho para propor uma ética que concilie a perspectiva de princípios, de regras e de direitos com a da ética do cuidado. Entretanto, a complementaridade entre a voz masculina e a voz feminina nem sempre é levada em consideração pelas partidárias da ética do cuidado que sugerem a substituição de perspectiva ética baseada em princípios e direitos por aquela do cuidado, a exemplo do que faz Noddings.

Se as vozes não são opostas ou excludentes, ao contrário do que Noddings indica ao propor seu modelo de ética do cuidado como uma alternativa ao modelo de princípios universais, torna-se inviável defender uma ética exclusivamente baseada na perspectiva dos relacionamentos de cuidado ao se considerar a abordagem de Gilligan. Quando se faz apenas uma das vozes permanecer, seja a masculina ou a feminina, leva-se adiante a estrutura conceitual da lógica da dominação, baseada em relações de poder que objetivam subjugar um sexo ao outro.

Ao evidenciar a existência de uma voz moral feminina, Gilligan não pretende sustentar a estrutura conceitual patriarcal, ao contrário, sugere que a voz feminina necessita ser ouvida e que por meio da inserção das mulheres nas mais diversas instituições sociais torna-se cada vez mais fácil para mulheres e homens alcançarem a maturidade moral em virtude da ampliação do espaço de diálogo entre os gêneros. Com isso, as mulheres passam a reconhecer a importância dos direitos que adquiriram, os quais lhes asseguram a própria participação social. Elas passam a conviver mais com princípios e regras e aplicá-los para além do âmbito do cuidado nas relações, diante do crescente número de situações que lhes permitem assumir a responsabilidade na tomada de decisões. Além disso, ao exercerem o seu raciocínio moral, as mulheres apresentam questões de responsabilidade nas relações sociais, oferecendo um caminho complementar à abordagem de regras e princípios na moralidade ${ }^{25}$. Ainda assim, a moralidade de responsabilidade que é desenvolvida nas mulheres mantém-se em tensão com a moralidade de direitos (regras e princípios) que a elas é imposta na participação na sociedade. Essa tensão, por sua vez, abre espaço para a busca da simetria na distribuição de poder entre homens e mulheres.

A complementaridade defendida por Gilligan sugere que as mulheres podem desenvolver uma compreensão lógica de suas relações com os outros, distanciando-se deles para equilibrar as 
reivindicações do eu e do outro na decisão moral, do mesmo modo que os homens podem desenvolver uma preocupação com os outros, isto é, uma responsabilidade contextual sem que para isso seja necessária sempre a aplicação de algum princípio ou o reconhecimento de algum direito. Embora a racionalidade feminina possa estar mais baseada em um sentimento de conexão em relação aos outros do que propriamente no reconhecimento de que o outro tem um direito a algo, por exemplo, isso não significa que as mulheres não realizam julgamentos morais coerentes a partir de razões plausíveis a serem aceitas pelos outros e baseadas na avaliação racional da situação.

Dessa forma, uma proposta de ética do cuidado que exclua princípios e normas universais distancia-se da própria abordagem de Gilligan. Além disso, se o feminismo é uma discussão sobre o poder na sociedade, segundo indicado por Lindemann ${ }^{26}$, e se ele propõe-se a combater o dualismo hierárquico entre o masculino e o feminino, que se constitui na fonte da assimetria de poder entre homens e mulheres, ao defender uma ética do cuidado em detrimento de uma ética de princípios, termina-se por prorrogar esse mesmo dualismo e ainda incorre-se no risco de reproduzir o estereótipo de que mulheres são guiadas exclusivamente pelas emoções. Em certos contextos de opressão, nos quais o cuidar é designado às mulheres, uma concepção de ética do cuidado pode inclusive provocar danos morais as próprias mulheres e mantê-las presas ao âmbito privado. Por isso, Cuomo alerta que a adoção precipitada de uma ética do cuidado leva adiante a condição social de submissão da mulher ${ }^{27}$.

Além disso, há outras limitações na proposta de Noddings que resultam do objetivo de conceber a ética do cuidado como um modelo alternativo ao da ética de princípios. A restrição do cuidado às relações próximas corresponde a um desses limites.

Na ética do cuidado, conforme concebida por Noddings, só há obrigação de cuidar dos que estão próximos. Embora a autora admita que a ética do cuidado não nega a possibilidade de cuidar de estranhos, podendo a cuidadora ser receptiva em relação ao estranho que não integra sua cadeia de cuidados $^{28}$, isso pode ser insuficiente para garantir o cuidado para com todos os que precisam dele e não têm alguém próximo que lhes assegure esse cuidado. Rachels pontua justamente que o problema da ética do cuidado situa-se na restrição do cuidado aos relacionamentos pessoais:

Fazer do relacionamento pessoal o papel principal da ética parece tanto uma idéia errônea como ignorar o restante. Uma abordagem mais sensível seria dizer que a vida ética inclui o cuidado com os relacionamentos pessoais e um interesse benevolente com as pessoas em geral ${ }^{29}$.

Por isso, a ética de princípios complementa a ética do cuidado, estabelecendo obrigações e deveres para além dos que estão próximos. É nesse sentido que se direciona Gilligan, ao afirmar que a maturidade moral da mulher permite-a compreender a moralidade masculina e integrá-la à 
sua. A ética do cuidado nas relações próximas não é suficiente para as mulheres que cada vez mais saem do âmbito privado para assumir ocupações no âmbito público. Assim, a complementaridade sugerida por Gilligan mostra-se mais adequada, uma vez que preenche o vazio deixado nos lugares que as relações de cuidado não conseguem englobar.

Ao restringir o cuidado às relações próximas, a ética do cuidado também se configura como uma perspectiva ética parcial por sugerir que uma maior atenção deva ser dada àqueles que estão mais próximos do agente cuidador em detrimento dos que dele se distanciam. A parcialidade tornase algo até mesmo necessário para o não rompimento de relacionamentos próximos. Ao mesmo tempo, permite que o agente cuidador manifeste uma conduta de indiferença para com os que não integram seu círculo de cuidados. Atendo-se a esse problema, Beauchamp e Childress afirmam que um julgamento parcial em favor daqueles com quem se mantém relacionamentos de cuidado tem de ceder lugar, pelo menos em algumas situações, à ação imparcial ${ }^{30}$. Ao analisar esse mesmo problema, Singer, Kuhse e Rickard distinguem entre dois âmbitos do pensar moral: o familiar e o público. No âmbito familiar, a parcialidade do cuidado, situada no nível intuitivo da moralidade, poderia ser acomodada e seria moralmente legítima, enquanto no âmbito público as decisões morais deveriam sempre ter por base a imparcialidade e o raciocínio de nível crítico ${ }^{31}$. A imparcialidade no âmbito público garante determinadas restrições que previnem situações de injustiça, sobretudo quando se argumenta a favor de uma análise contextual do que compõe o cuidado em cada situação, a fim de evitar a marginalização de interesses. Novamente, prevalece a ideia de uma complementaridade entre a parcialidade de uma ética do cuidado e a imparcialidade de uma ética de princípios.

Gilligan também não fornece base para a exigência da reciprocidade no cuidado das relações, presente na abordagem de Noddings. Na concepção de Noddings, quando o objeto do cuidado não responde de algum modo positivo aos esforços daquele que cuida, não se estabelece uma relação de cuidado $^{32}$. Aqui, pode-se questionar se é mesmo sempre possível exigir a reciprocidade no cuidado. Certamente, há muitas situações nas quais um cuidado faz-se moralmente necessário, ainda que o objeto do cuidado não responda positivamente, interaja ou reconheça que é cuidado por não ter condições físicas ou psíquicas de oferecer essa reciprocidade. Ao mesmo tempo, a exigência da reciprocidade limita significativamente a abrangência das relações de cuidado.

O cuidado para com os que não integram o círculo, isto é, àqueles que não têm como garantir a reciprocidade numa relação de cuidado, pode parecer um ideal mais abstrato, porém, é preciso que seja mantido para evitar que a situação de pessoas distantes torne-se ainda pior pelo fato de muitas vezes já se encontrarem em situações difíceis nas quais não recebem cuidado. Se mesmo com leis e direitos básicos assegurados, muitas vezes não é possível garantir um mínimo digno de sobrevivência para as pessoas, certamente não é com uma proposta de cuidado restrita às relações com pessoas próximas que se conseguirá ampliar o bem-estar. 
É preciso pensar também nos possíveis conflitos que podem vir a ocorrer entre círculos de cuidado de diferentes cuidadores. Beauchamp e Childress afirmam que "assim como muitas teorias morais enfrentam conflitos de princípios e de direitos, a ética do cuidar enfrenta conflitos entre responsabilidades" ${ }^{{ }_{33}}$. Noddings critica a situação atual de violência na qual o mundo se encontra e afirma que muitas coisas acontecem em nome de princípios. Todavia, a autora não considera o fato de que podem ocorrer conflitos entre os círculos de cuidado de duas pessoas que tendem a proteger aqueles que pertencem ao seu próprio conjunto de relações. Uma ética de princípios integrada à ética do cuidado pode auxiliar a resolver conflitos entre esses diferentes círculos de cuidado.

Importa notar ainda, que a ética do cuidado é contraditória ao afirmar que princípios universalizáveis são desnecessários numa teoria ética e, ao mesmo tempo, exigir a universalização da atitude do cuidado nas relações. Ao universalizar a atitude do cuidado, a ética feminista já admite a existência de pelo menos um princípio universal, a saber, o da necessidade de o cuidado permear os relacionamentos pessoais. Ademais, embora negue a importância de princípios e leis, certamente a ética do cuidado não concordaria que fossem infringidos os direitos das mulheres que lhes são universalmente assegurados. Nesse sentido, Francione observa que a ética do cuidado não consegue transcender a perspectiva dos direitos, pois admitiria um princípio universal de proibição da violência em relação às mulheres. $\mathrm{O}$ autor defende então que certas regras precisam ser universais, e certos princípios universais precisam existir. No entender de Francione, o princípio de não permitir que as pessoas sejam usadas pelo agente cuidador como um meio para que ele garanta o cuidado para com os que integram seu círculo de relações próximas é um exemplo de princípio que precisaria ser universalizado ${ }^{34}$.

Tendo por base os apontamentos levantados, pode-se questionar até que ponto é possível pensar em um sistema teórico coerente, somente baseado no cuidado nas relações, onde regras e leis de pretensão universal, bem como a preocupação em alcançar a justiça e a imparcialidade nas decisões morais percam sua relevância. Se há realmente um cuidado natural inerente aos seres humanos, conforme defende Noddings, por que esse cuidado deve ficar restrito aos que estão próximos da cuidadora e não ser desenvolvido, visando alcançar o maior número de pessoas possíveis? Por que o cuidado precisa excluir exigências de racionalidade lógica e adequação a princípios que se pretendem universais, tornando-se uma alternativa à ética de princípios?

Noddings parece ter percebido os limites de sua teoria ao escrever o Preface to the Second Edition do seu livro. Nesse prefácio, ela afirma que apesar de ter sugerido na primeira edição de seu livro que princípios e regras possam não ser centrais para a vida moral, ela não os considera sem importância e admite que mesmo mulheres os empregam para justificar muitos de seus atos, sobretudo aqueles que podem causar algum dano a alguém ${ }^{35}$. Antes disso, a autora já tinha afirmado que apesar do abismo entre o masculino e o feminino, ela não pretendeu "colocar os homens e as mulheres em campos opostos" ao descrever a ética do cuidado. Ao contrário, objetivava mostrar que 
a existência das diferenças indica o caminho para o início de um diálogo que vise "alcançar uma transcendência fundamental do masculino e do feminino nas questões morais" ${ }^{36}$. A própria proposta de Noddings, de uma sociedade baseada na ética do cuidado, pressupõe essa transcendência para que a prática educativa do cuidado torne-se viável.

Essa transcendência entre as vozes diferentes está próxima da noção de complementaridade enunciada por Gilligan, a qual sugere que quando alcançam a maturidade moral, o pensamento de homens e mulheres acerca da moralidade é bem menos diferente do que parece ser ao longo do processo de desenvolvimento. Desse modo, a ênfase inicialmente atribuída por Gilligan à diferença entre a forma de pensar masculina e a feminina em relação à moralidade, termina por perder espaço em detrimento do reconhecimento de que a maturidade moral de ambos os sexos leva à integração desses modos diversos de pensar.

Em suma, as feministas devem reivindicar reformulações éticas, por meio das quais o modo de raciocínio feminino seja levado em consideração e deixe de ser visto como um problema no desenvolvimento, mas sem exigir que ele seja o único existente. Em outros termos, é preciso dar atenção a valores como o cuidado e a reciprocidade nas relações e ao ponto de vista epistemológico e moral de um grupo subordinado, a saber, as mulheres ${ }^{37}$. A noção de cuidado não precisa ser abandonada. Ao mesmo tempo, não se deve rejeitar precipitadamente o "eu autônomo masculino" para adotar o "eu relacional feminino" como a base de uma teoria ética, conforme salienta Gaard" Também Baier pontua a importância de buscar uma teoria moral caracterizada pela completude, isto é, uma teoria que não ignore o que se construiu até o presente e que procure acomodar o pensamento de homens e mulheres a fim de assegurar a complementaridade entre ambas as perspectivas e abranger com coerência a realidade ampla da moralidade ${ }^{39}$. Portanto, nem a moralidade feminina, nem a masculina é melhor ou pior; ambas são apenas diferentes e complementares, podendo ser integradas pelos agentes morais. Logo, nem uma, nem outra deve ser excluída de uma proposta ética.

\section{CONSIDERAÇÕES FINAIS}

A discussão aqui realizada, após a apresentação de alguns elementos centrais da proposta moral teórica de ética do cuidado de Nel Noddings, centrou-se em torno da averiguação de pontos de divergência entre Gilligan e Noddings. A partir do exposto, tem-se que não é possível conceber uma ética do cuidado como uma alternativa à ética de princípios com base nos estudos que Gilligan realizou em torno da identificação de duas vozes morais distintas. Gilligan defende a complementaridade entre a voz feminina e a voz masculina, sem que uma delas seja considerada em uma teoria moral em detrimento da outra. Uma teoria ética pode, assim, integrar a abordagem 
de princípios e direitos com a da responsabilidade contextual derivada das relações de cuidado.

Além disso, apesar da importância de alguns aspectos levantados pela ética do cuidado - como o fato de chamar a atenção para um tema até então negligenciado nas teorias éticas, a saber, o da experiência do cuidado e o da compreensão contextual da situação do outro na relação interpessoal -, considera-se que a ética precisa extrapolar os relacionamentos próximos mantidos pelo agente moral com as pessoas. Para tanto, alguns princípios, obrigações e regras podem ser indispensáveis para guiar a responsabilidade do agente moral.

Em virtude disso, a complementaridade e a integração entre ambas as perspectivas morais, ao invés da superveniência de uma em detrimento da outra, é um caminho mais adequado quando se leva em conta o estudo acerca do desenvolvimento moral de Gilligan. A complementaridade supera a incompletude de uma ética do cuidado, que sugere sempre favorecer aqueles com quem o agente moral possui um relacionamento de proximidade; ao mesmo tempo, supera a limitação de uma ética de princípios que exige o raciocínio imparcial e abstrato - algo que pode não ser possível em todas as situações.

Nesse sentido, é fundamental o reconhecimento da contribuição da denominada voz feminina para quebrar o estereótipo da menor capacidade moral das mulheres, resultante de uma construção machista do gênero feminino, com o fim de eliminar a assimetria nas relações de poder entre homens e mulheres e, por conseguinte, desconstruir a estrutura social que se sustenta sobre essa assimetria, caracterizada por usos patriarcais da razão, dentre outras formas de preconceitos.

A partir disso, torna-se possível ir além dos limites de gênero em uma teoria ética: nem só a voz masculina, nem só a voz feminina devem ser ouvidas numa teoria moral, mas ambas devem ser contempladas. Uma teoria moral completa considera relevantes princípios e direitos, bem como a responsabilidade contextual que origina o cuidado e permite sua expansão nas mais diversas práticas sociais. 


\section{NOTAS}

1 Doutoranda do Programa de Pós-Graduação em Filosofia, da Área de Ética e Filosofia Política, da Universidade Federal de Santa Catarina.

2 Para este artigo, utilizou-se a tradução da obra para a língua portuguesa: GILLIGAN, Carol. Teoria psicológica e desenvolvimento da mulher. Lisboa: Fundação Calouste Gulbenkian, 1997.

3 Ibid., p. 10; 16.

4MITCHELL, Katie. Women's Morality: A Test of Carol Gilligan's Theory. Journal of Social Distress and the Homeless, v. 11, n. 1, p. 81-110, jan. 2002, p. 107.

5BAIER, Annette. What do Women Want in a Moral Theory?, Noûs, v. 19, n. 1, p. 53-63, mar. 1985, p. 53.

6 NODDINGS, Nel. O cuidado: uma abordagem feminina à ética e à educação moral. São Leopoldo: Unisinos, 2003, p. 11.

7 Ibid., p. 11.

8 Ibid., p. 16.

9 A ideia de "separação" aqui referida Gilligan explica com base em Chodorow, a qual afirma que a existência das diferenças entre homens e mulheres nas experiências de individualização e relacionamento deriva do Complexo de Édipo, que origina uma "separação" entre mãe e filho, enquanto mãe e filha mantêm uma relação com base na "ligação" ao longo da vida, o que permite às mulheres adquirir uma base mais sólida para perceberem as necessidades e os sentimentos dos outros como se fossem delas próprias. Dessa forma, as relações e especialmente as situações de dependência são sentidas diferentemente por homens e por mulheres: "[...] a masculinidade é definida pela separação, enquanto que a feminilidade é definida pela ligação". Por isso, "a identidade sexual masculina é ameaçada pela intimidade, enquanto que a identidade sexual feminina é ameaçada pela separação". Em outros termos, a identidade masculina se constrói na sociedade por meio da separação e a identidade feminina é despertada pela relação de afetividade com outra pessoa (GILLIGAN, op. cit., p. 19-20).

10 NODDINGS, op. cit., p. 14.

11 Ibid., p. 45.

12 Ibid., p. 20.

13 Ibid., p. 14.

14 Ibid., p. 118.

15 O "cuidado natural", de acordo com Noddings, deriva do reconhecimento da ligação natural entre todos os seres da espécie humana, sendo acessível a todos os seres humanos. É esse cuidado que precede o "cuidado ético" e o torna possível (Ibid., p. 63). Dito de outro modo, a partir do sentimento natural pode desenvolver-se o sentimento ético: a inclinação pela moralidade deriva de um cuidado inato, isto é, um impulso natural de agir em beneficio do outro que antecede a própria moralidade e a própria exigência de cuidar. É um sentimento interno com o qual as pessoas nascem que as leva a responder as necessidades do outro antes mesmo que alguma obrigação externa lhes seja imposta (Ibid., p. 108-110). Apesar desse cuidado natural de origem biológica, homens e mulheres diferenciam-se em virtude de sua estrutura psicológica. Assim, as mulheres mantêm-se próximas do cuidado natural e desenvolvem o cuidado ético nas relações com os outros, enquanto a tendência entre os homens é se afastar desse cuidado em busca de direitos, leis e princípios por meio dos quais possam se proteger.

16 Ibid., p. 16

17 Ibid., p. 41.

18 Ibid., p. 113.

19 Ibid., p. 96-97.

20 NODDINGS, Nel. Preface to Second Edition. In: . Carin: a Feminine Approach to Ethics and Moral

Education. 2 ed. Los Angeles: University of California Press, 2003a, p. xiii.

21 GILLIGAN, op. cit., p. 36.

22 Ibid., p. 158.

23 Ibid., p. 159.

24 Ibid., p. 270.

25 Ibid., p. 202-204.

26 LINDEMANN, Hilde. An Invitation to Feminist Ethics. New York: McGraw Hill, 2006, p. 9.

27 CUOMO, Christine J. Unravelling the Problems in Ecofeminism. Environmental Ethics, v. 14, n. 4, p. 351-363, Winter 1992, p. 354.

28 NODDINGS, op. cit., p. 68.

29 Ibid., p. 171.

30 BEAUCHAMP, Tom L.; CHILDRESS, James F. Princípios de Ética Biomédica. São Paulo: Loyola, 2002, p. 112. 
31 KUHSE, Helga; SINGER, Peter; e RICKARD, Maurice. Reconciling Impartial Morality and a Feminist Ethic of Care. The Journal of Value Inquiry, n. 32, p. 451-463, 1998, p. 455-456; 459-460.

32 NODDINGS, op. cit., 2003a, p. xiv.

33 BEAUCHAMP; CHILDRESS, op. cit., p. 106.

34 FRANCIONE, Gary. Ecofeminism and Animal Rights: a Review of Beyond Animal Rights: a Feminist Caring Ethic for the Treatment of Animals. In: Animals as persons: essays on the abolition of animal exploitation. New York: Columbia University Press, 2008, p. 204; 208.

35 NODDINGS, op. cit., 2003a, p. xiv.

36 Idem., 2003, p. 17.

37 WARREN, Karen J. Feminism and Ecology: Making Connections. Environmental Ethics, v. 9, n. 1, p. 3-20, Spring 1987, p. 11.

38 GAARD, Greta. Ecofeminism and Wilderness. Environmental Ethics, v. 19, n. 1, p. 5-24, Spring 1997, p. 15.

39 BAIER, op. cit., p. 55-56. 


\section{REFERÊNCIAS}

BAIER, Annette. What do Women Want in a Moral Theory? In: Noûs. v. 19, n. 1, mar. 1985, p. 53-63.

BEAUCHAMP, Tom L.; CHILDRESS, James F. Princípios de Ética Biomédica. São Paulo: Loyola, 2002.

CUOMO, Christine J. Unravelling the Problems in Ecofeminism. In: Environmental Ethics. v. 14, n. 4, Winter 1992, p. 351-363.

FRANCIONE, Gary. Ecofeminism and Animal Rights: a Review of Beyond Animal Rights: a Feminist Caring Ethic for the Treatment of Animals. In: , Gary. Animals as Persons: Essays on the Abolition of Animal Exploitation. New York: Columbia University Press, 2008.

GAARD, Greta. Ecofeminism and Wilderness. In: Environmental Ethics. v. 19, n. 1, Spring 1997, p. 5-24.

GILLIGAN, Carol. Teoria psicológica e desenvolvimento da mulher. Lisboa: Fundação Calouste Gulbenkian, 1997.

KUHSE, Helga; SINGER, Peter; e RICKARD, Maurice. Reconciling Impartial Morality and a Feminist Ethic of Care. In: The Journal of Value Inquiry, n. 32, 1998, p. 451-463.

LINDEMANN, Hilde. An Invitation to Feminist Ethics. New York: McGraw Hill, 2006.

MITCHELL, Katie. Women's Morality: A Test of Carol Gilligan's Theory. In: Journal of Social Distress and the Homeless, v. 11, n. 1, jan. 2002, p. 81-110.

NODDINGS, Nel. O cuidado: uma abordagem feminina à ética e à educação moral. São Leopoldo: Unisinos, 2003.

, Nel. Preface to Second Edition. In: , Nel. Carin: a Feminine Approach to Ethics and Moral Education. 2 ed. Los Angeles: University of California Press, 2003a.

WARREN, Karen J. Feminism and Ecology: Making Connections. In: Environmental Ethics, v. 9, n. 1, Spring 1987, p. 3-20. 